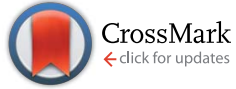

Cite this: Chem. Sci., 2015, 6, 3881

Received 29th March 2015 Accepted 13th April 2015

DOI: $10.1039 / \mathrm{c} 5 \mathrm{sc0} 01126 \mathrm{~d}$

www.rsc.org/chemicalscience

\title{
Significant improvement of oxidase activity through the genetic incorporation of a redox- active unnatural amino acid $\dagger$
}

\author{
Yang Yu,,$^{\mathrm{c}}$ Qing Zhou,,$^{\mathrm{b}}$ Li Wang,,$^{\mathrm{ab}}$ Xiaohong Liu, ${ }^{\mathrm{b}}$ Wei Zhang, ${ }^{\mathrm{b}}$ Meirong Hu, ${ }^{\mathrm{b}}$ \\ Jianshu Dong, ${ }^{\text {b }}$ Jiasong Li, ${ }^{\text {ab }}$ Xiaoxuan Lv, ${ }^{\text {b }}$ Hanlin Ouyang, ${ }^{c}$ Han Li, ${ }^{\text {b } F e n g ~ G a o, ~}{ }^{\text {b }}$ \\ Weimin Gong, ${ }^{b}$ Yi Lu*c and Jiangyun Wang ${ }^{\star b}$
}

\begin{abstract}
While nature employs various covalent and non-covalent strategies to modulate tyrosine $(\mathrm{Y})$ redox potential and $\mathrm{p} K_{\mathrm{a}}$ in order to optimize enzyme activities, such approaches have not been systematically applied for the design of functional metalloproteins. Through the genetic incorporation of 3-methoxytyrosine $(\mathrm{OMeY})$ into myoglobin, we replicated important features of cytochrome c oxidase $(\mathrm{CcO})$ in this small soluble protein, which exhibits selective $\mathrm{O}_{2}$ reduction activity while generating a small amount of reactive oxygen species (ROS). These results demonstrate that the electron donating ability of a tyrosine residue in the active site is important for $\mathrm{CcO}$ function. Moreover, we elucidated the structural basis for the genetic incorporation of $\mathrm{OMeY}$ into proteins by solving the $\mathrm{X}$-ray structure of $\mathrm{OMeY}$ specific aminoacyl-tRNA synthetase complexed with OMeY.
\end{abstract}

\section{Introduction}

Designing artificial enzymes with higher activity and selectivity can reveal important features responsible for tuning enzymatic activities, and result in efficient catalysts for practical applications. ${ }^{1-9}$ One key mechanism which accounts for the high activity of many natural enzymes is the fine-tuning of the redox potential of tyrosine residues. In order to optimize the electron transfer rate to enable enzymatic turnover with high efficiency and selectivity, nature has exploited various strategies, such as post-translational modifications including topa quinone in copper amine oxidases, the Tyr-His crosslink in CcO, the TyrCys crosslink in galactose oxidases (GO), and histidine base association in photosystem II (PSII). ${ }^{10-16}$ Such strategies are highly effective in modulating the redox potential (from $0.1 \mathrm{~V}$ to $1.1 \mathrm{~V} v s$. NHE) and $\mathrm{p} K_{\mathrm{a}}$ of specific tyrosine residues to suit the specific needs of various reactions, thereby greatly enhancing enzyme activity. ${ }^{\mathbf{1 0 - 1 6}}$ However, it remains difficult to perform rational tuning of the redox potential and $\mathrm{p} K_{\mathrm{a}}$ of specific tyrosine residues in designed metalloproteins. Here we show that,

${ }^{a}$ School of Life Sciences, University of Science and Technology of China, Hefei, Anhui, 230026, China

${ }^{b}$ Laboratory of RNA Biology, Institute of Biophysics, Chinese Academy of Sciences, 15 Datun Road, Chaoyang District, Beijing, 100101, China. E-mail: jwang@ibp.ac.cn

${ }^{c}$ Center of Biophysics and Computational Biology and Department of Chemistry, University of Illinois at Urbana-Champaign, Urbana, Illinois, 61801, USA. E-mail: yi-lu@illinois.edu

$\dagger$ Electronic supplementary information (ESI) available: Experimental procedures. See DOI: $10.1039 / \mathrm{c} 5 \mathrm{sc} 01126 \mathrm{~d}$

\$ These authors contributed equally to this work. through the genetic incorporation of redox-active unnatural amino acids with desirable redox potential, a significant improvement in oxidase activity can be achieved.

During the final stage of aerobic respiration, $\mathrm{CcO}$ catalyzes the efficient reduction of $\mathrm{O}_{2}$ to $\mathrm{H}_{2} \mathrm{O}$, which requires rapid transfer of four electrons and four protons to the oxygen substrate, preventing the release of toxic reactive oxygen species (ROS) ${ }^{15}$ The key step in oxygen reduction is the scission of the $\mathrm{O}-\mathrm{O}$ bond in the ferric-superoxo intermediate, leading to the formation of an intermediate $\mathrm{P}$ in the heme $a_{3} / \mathrm{Cu}_{\mathrm{B}}$ binuclear active site. ${ }^{17}$ The donor of a proton and electron for this reaction has been suggested to be a unique tyrosine residue covalently cross-linked to one of the histidine ligands of $\mathrm{Cu}_{\mathrm{B}}$. This Tyr-His crosslink is thought to lower the $\mathrm{p} K_{\mathrm{a}}$ and redox potential of the tyrosine residue, thus facilitating proton and electron donation to the oxygen substrate. ${ }^{15,18}$

In previous studies, we have reported the introduction of various tyrosine analogs into a myoglobin-based functional oxidase, ${ }^{19,20}$ including imiTyr ${ }^{19}$ which mimics the Tyr-His crosslink in $\mathrm{CcO}$, and a series of halogenated Tyr analogs with decreasing $\mathrm{p} K_{\mathrm{a}}{ }^{21}$ By replacing Tyr33 with imiTyr and halogenated tyrosine analogs, the activity and selectivity of the functional oxidase increases. Moreover, the oxidase activity is correlated with the $\mathrm{p} K_{\mathrm{a}}$ of the phenol ring of Tyr or its halogenated analogs, indicating the active role of Tyr in the oxidase reaction. However, since the reduction potentials of halogenated Tyr analogs are closely related to their $\mathrm{p} K_{\mathrm{a}}$, we have not yet addressed whether fine-tuning the redox potential of the tyrosine residue influences oxidase activity. Herein we report genetic incorporation of a tyrosine analog, 3-methoxy tyrosine 
$(\mathrm{OMeY})$, that has a lower reduction potential but similar $\mathrm{p} K_{\mathrm{a}}$ compared to Tyr, to provide evidence that tuning the reduction potential of Tyr is also important for oxidase activity.

\section{Results and discussion}

We first attempted to genetically incorporate two previously reported Tyr analogs, 3,4-dihydroxy-L-phenylalanine (Dopa) ${ }^{22}$ and 3-amino-tyrosine $\left(\mathrm{NH}_{2} \mathrm{Y}\right),{ }^{23}$ which have lower redox potentials than tyrosine, into the $33 \mathrm{rd}$ position of $\mathrm{Cu}_{\mathrm{B}} \mathrm{Mb}$. However, yields of these mutant proteins were quite low, preventing further characterization. One explanation for these results is that Dopa and $\mathrm{NH}_{2} \mathrm{Y}$ can both undergo an irreversible twoelectron oxidation reaction to afford dopaquinone, which is well-known to be highly reactive and to play pivotal roles in melanogenesis (Fig. S1†). ${ }^{24}$ This problem may be exacerbated when an oxidase or oxidase-mimicking enzyme is overexpressed in E. coli. In order to circumvent this problem, we decided to genetically incorporate OMeY, because its redox potential at pH 7 is $179 \mathrm{mV}$ lower than that of Tyr (Fig. S2 $\dagger$ ), but it cannot easily undergo the two-electron oxidation reaction.

The difficulty of synthesizing unnatural amino acid analogs of Tyr, such as OMeY, is often a limiting factor for the systematic investigation of the role of Tyr in different enzymes. Enzymatic transformation by native or engineered tyrosine phenol lyase (TPL), as demonstrated herein, has been proven to be a powerful tool for synthesizing tyrosine analogs (Scheme 1). ${ }^{25,26}$ To synthesize OMeY, we first tried to transform 2-methoxyphenol to OMeY by using the wild type Symbiobacterium sp. SC1 TPL, which is more thermostable than Citrobacter freundii (ATCC8090). ${ }^{27}$ However, we could not detect any OMeY by ninhydrin thin-layer chromatography (TLC) assay. To evolve a TPL mutant that could efficiently catalyze this transformation, we screened a TPL library pEt-SymbTPL, which harbors random mutations at sites Phe36, Met288, Met379, and Phe448 as previously reported, ${ }^{26,28}$ and found that one clone efficiently catalyzed the synthesis of OMeY, as confirmed by mass spectrometry after purification of the product by HPLC (Fig. S3-S4 $\dagger$ ). DNA sequencing revealed that this clone contains the Met379Val mutation. Molecular modeling indicated that the Met379Val mutation results in a significant enlargement of the enzyme pocket to allow for optimal interaction between the enzyme and the OMeY substrate (Fig. S5†). The reduction potential of OMeY is $179 \mathrm{mV}$ lower than that of Tyr at $\mathrm{pH} 7$, whereas the $\mathrm{p} K_{\mathrm{a}}$ values of $\mathrm{OMeY}$ and tyrosine are similar (Fig. S2 and $\mathrm{S} 6 \dagger$ ).

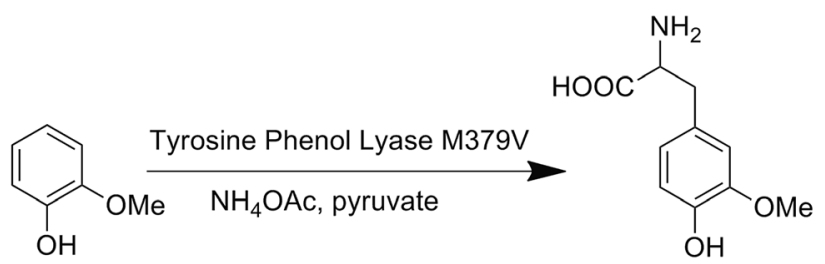

Scheme 1 A biosynthetic route to OMeY, catalyzed by the TPL mutant M379V.
To selectively incorporate $\mathrm{OMeY}$ at defined sites in proteins, a mutant Methanocaldococcus jannaschii tyrosyl amber suppressor tRNA (MjtRNA $\left.\mathrm{Tyr}_{\mathrm{Ty}}^{\mathrm{CU}}\right) /$ tyrosyl-tRNA synthetase (MjTyrRS) pair was evolved that uniquely specifies OMeY in response to the TAG codon, as previously reported. ${ }^{19}$ The evolved TyrRS (Fig. S7-S8†), named OMeYRS, has six mutations: Tyr32Glu, Leu65Ser, His70Gly, Tyr109Gly, Asp158Asn, and Leu162Val.

To determine if OMeY could be incorporated into proteins with high efficiency and fidelity, an amber stop codon was substituted for Ser4 in sperm whale myoglobin (Mb). Protein production was carried out in $E$. coli in the presence of the selected synthetase (OMeYRS), MjtRNA Tyr $_{\text {CUA }} 1 \mathrm{mM} \mathrm{OMeY,} \mathrm{or}$ in the absence of OMeY as a negative control. Analysis of the purified protein by SDS-PAGE showed that full-length myoglobin was expressed only in the presence of $\mathrm{OMeY}$ (Fig. 1A), indicating that OMeYRS was specifically active with OMeY but inactive with natural amino acids. The yield for this mutant myoglobin was $10 \mathrm{mg} \mathrm{\textrm {L } ^ { - 1 }}$. By comparison, the yield of wild-type sperm whale myoglobin (WTMb) was $50 \mathrm{mg} \mathrm{L}^{-1}$. ESIMS analysis of the Ser4 OMeY mutant myoglobin gave an observed average mass of $18461.6 \mathrm{Da}$, in agreement with the calculated mass of 18461.1 Da (Fig. 1B).

To test whether the catalytic activity could be improved through the genetic incorporation of unnatural amino acids, we replaced Phe33 in $\mathrm{Cu}_{\mathrm{B}} \mathrm{Mb}$ with $\mathrm{OMeY}$, generating Phe33OMeY$\mathrm{Cu}_{\mathrm{B}} \mathrm{Mb}$ (Fig. 2). This mutant showed a similar UV-vis spectrum to that of Phe33Tyr- $\mathrm{Cu}_{\mathrm{B}} \mathrm{Mb}$ (Fig. S9 $\dagger$ ), indicating that the overall environment around the heme center should also be similar. ${ }^{20}$
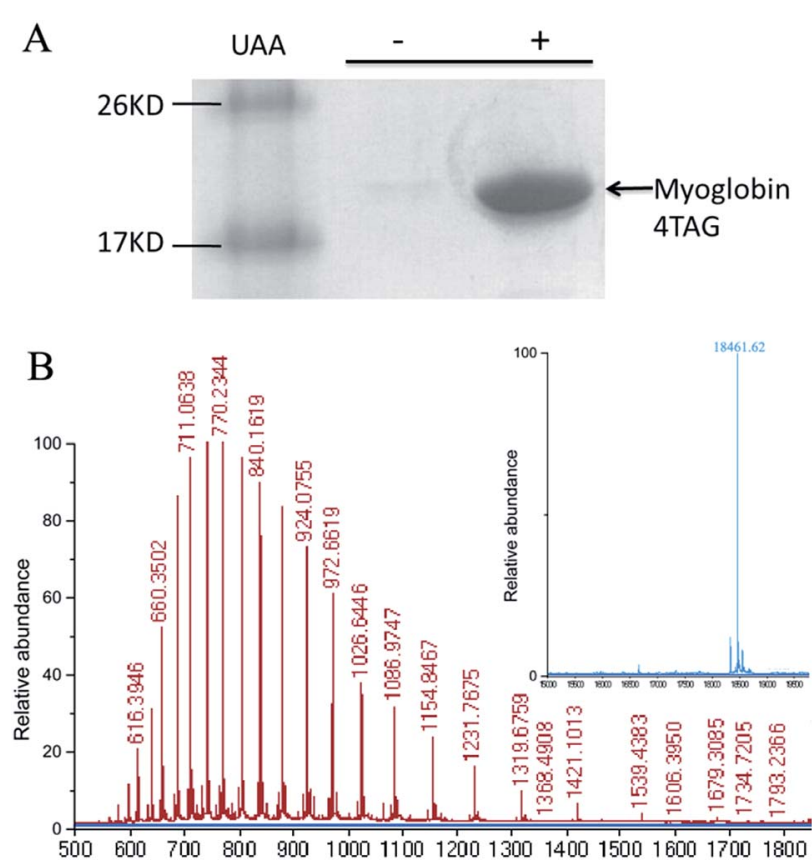

Fig. 1 (A) SDS-PAGE of expression of TAG4 myoglobin mutant in the presence (right lane) and absence (middle lane) of $1 \mathrm{mM}$ unnatural amino acid OMeY (UAA). (B) ESI-MS of the TAG4 mutant. The inset shows the deconvoluted spectrum; expected mass: $18461 \mathrm{Da}$, found: 18461.62 Da. 


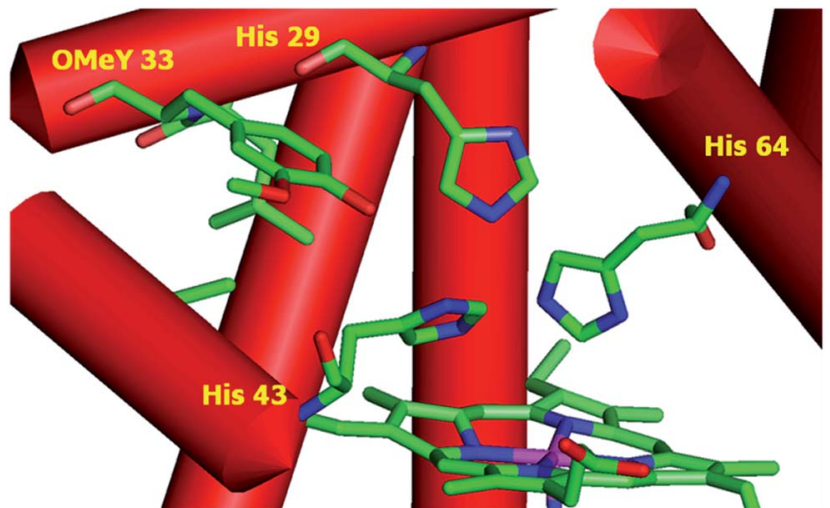

Fig. 2 Structural model of OMeY myoglobin mutant, constructed based on the crystal structure of Phe33Tyr-CuB Mb ( $p d b$ code 4FWX).

We then measured the rates of oxygen reduction catalyzed by $6 \mu \mathrm{M}$ myoglobin mutants with an $\mathrm{O}_{2}$ electrode in $20 \mathrm{mM}$ tris(hydroxymethyl)aminomethane (Tris) buffer at $\mathrm{pH}$ 7.4. Ascorbate (1000 equivalents) and tetramethyl- $p$-phenylenediamine dihydrochloride (TMPD, 100 equivalents) were used as reductant and redox mediator, respectively. ${ }^{29}$ To differentiate between reactive oxygen species (ROS) and water products, we used catalase and superoxide dismutase (SOD), which catalyze the disproportionation of hydrogen peroxide or superoxide into oxygen and water. If $\mathrm{O}_{2}$ consumption results in the formation of ROS but not water, the $\mathrm{O}_{2}$ reduction rate should decrease in the presence of catalase and SOD, because they will convert ROS to $\mathrm{O}_{2}$. By comparing the rates of reduction in the presence and absence of ROS scavenger, the portions of $\mathrm{O}_{2}$ reduction due to water formation (in blue) and due to ROS formation (in red) can be calculated (Fig. 3A and Table S2 $\dagger$ ). Our results show that Phe33Tyr- $\mathrm{Cu}_{\mathrm{B}} \mathrm{Mb}$ was able to reduce $\mathrm{O}_{2}$ at a rate of $6.5 \mu \mathrm{M}$ $\min ^{-1}$, with $51 \%$ of $\mathrm{O}_{2}$ being converted into water. In contrast, Phe33OMeY-Cu $\mathrm{Cu}_{\mathrm{B}} \mathrm{Mb}$ exhibited significantly higher oxidase activity at $15.0 \mu \mathrm{M} \mathrm{min}^{-1}$ for $\mathrm{O}_{2}$ reduction, with $82 \%$ conversion of $\mathrm{O}_{2}$ into water. Similarly to the case of Phe33Tyr- $\mathrm{Cu}_{\mathrm{B}} \mathrm{Mb}$, addition of copper to Phe $33 \mathrm{OMeY}-\mathrm{Cu}_{\mathrm{B}} \mathrm{Mb}$ did not increase oxidase activity. ${ }^{20}$ Since the $\mathrm{p} K_{\mathrm{a}}$ of $\mathrm{OMeY}$ (Fig. $\mathrm{S} 6 \dagger$ ) is similar to that of Tyr, the lower redox potential of OMeY is likely responsible for the increased oxidase activity and $\mathrm{O}_{2}$ reduction selectivity of Phe33OMeY-Cu${ }_{B} \mathrm{Mb}$.

To further demonstrate the robustness of the best oxidasemimicking enzyme, Phe33OMeY- $\mathrm{Cu}_{\mathrm{B}} \mathrm{Mb}$, we carried out multiple turnover experiments (Fig. 3B). Phe33OMeY-Cu $\mathrm{B}_{\mathrm{B}} \mathrm{Mb}$ was able to catalyze $\mathrm{O}_{2}$ reduction for more than 1100 turnovers without significant reduction of catalytic rate. Under similar conditions, Phe33Tyr- $\mathrm{Cu}_{\mathrm{B}} \mathrm{Mb}$ could only catalyze the reaction for fewer than 500 turnovers. ${ }^{20}$

Previous studies with various halogenated Tyr analogs in an oxidase model have shown that oxidase activity is correlated with the $\mathrm{p} K_{\mathrm{a}}$ of Tyr or its analogs, however, correlation between oxidase activity and reduction potential at $\mathrm{pH} 7$ is weak. Since Tyr oxidation at neutral $\mathrm{pH}$, when Tyr is protonated, is a process coupled with the loss of a proton, the reduction potential of Tyr is influenced by $\mathrm{p} K_{\mathrm{a}}$. It is hard to separate the effect of $\mathrm{p} K_{\mathrm{a}}$ from
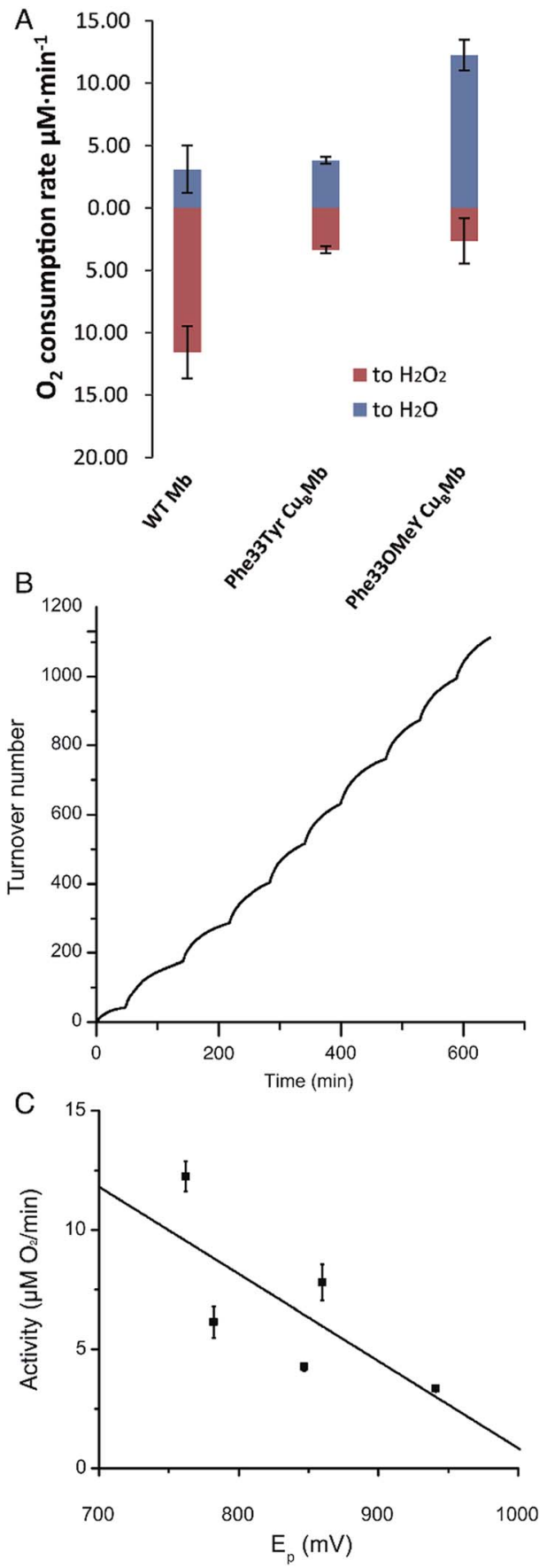

Fig. 3 (A) Rates of oxygen reduction to form either water (blue) or ROS (red) catalyzed by $6 \mu \mathrm{M}$ WTMb, Phe33Tyr-CuBMb or Phe33OMeY$\mathrm{Cu}_{\mathrm{B}} \mathrm{Mb}$. (B) $\mathrm{O}_{2}$ reduction turnover number for Phe33OMeYCu $\mathrm{Bb}_{\mathrm{B}} \mathrm{Mb}$, measured during the stepwise addition of $\mathrm{O}_{2}$. (C) Plot of oxidase

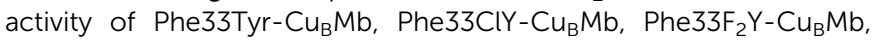

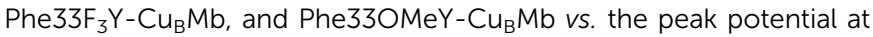
$\mathrm{pH} 7\left(E_{\mathrm{p}}\right)$ of the corresponding Tyr and Tyr analogs. $E_{\mathrm{p}}$ values measured by cyclic voltammetry were $941 \mathrm{mV}$ for Tyr, $847 \mathrm{mV}$ for ClY, $782 \mathrm{mV}$ for $\mathrm{F}_{2} \mathrm{Tyr}, 860 \mathrm{mV}$ for $\mathrm{F}_{3} \mathrm{Y}$, and $762 \mathrm{mV}$ for $\mathrm{OMeY}$. Abbreviations: CIY, 3chlorotyrosine; $F_{2} Y, 3,5$-difluorotyrosine; $F_{3} Y, 2,3,5$-trifluorotyrosine.

the reduction potential of Tyr. As OMeY has a much lower reduction potential but similar $\mathrm{p} K_{\mathrm{a}}$ to Tyr, it is clear that decreasing the reduction potential, similar to decreasing the 
$\mathrm{p} K_{\mathrm{a}}$, also enhances oxidase activity (Fig. 3C). The correlation of reduction potential/p $K_{\mathrm{a}}$ with oxidase activity is consistent with the active role of Tyr in the oxidase reaction, as previous studies have shown that a tyrosyl radical is formed during the oxygen reduction reaction of the $\mathrm{Mb}$-based functional oxidase. ${ }^{30}$

Unnatural Tyr analogs as spectroscopic or functional probes have been developed to study the function of Tyr in different enzymes. Halogenated Tyr analogs have different $\mathrm{p} K_{\mathrm{a}}$ values, as well as distinct EPR signals, ${ }^{21,25}$ making them useful for pinpointing the location of the tyrosyl radical intermediate and the proton donating ability of Tyr. Dopa and $\mathrm{NH}_{2} \mathrm{Y}$ have decreased reduction potential..$^{22,23}$ They are used in reductive enzymes as they are susceptible to oxidative damage. OMeY has a lower reduction potential than Tyr, yet is relatively stable under oxidative conditions, making it suitable for studying oxidative enzymes, such as cytochrome c oxidase, galactose oxidase, and lytic polysaccharide monooxygenase.

\section{Conclusions}

In summary, by incorporation of OMeY, an analog with a 179 $\mathrm{mV}$ lower reduction potential and similar $\mathrm{p} K_{\mathrm{a}}$ to Tyr, into a Mbbased functional oxidase, we found that the oxidase activity of the protein is correlated with the reduction potential of active site Tyr or its analogs. This further reveals the active role of Tyr in the oxidase reaction.

Tyr is an important residue for electron transfer ${ }^{31}$ as well as catalysis, ${ }^{14}$ due to its redox activity and proton-coupled electron transfer ability. Nature has evolved different ways of conducting post-translational modifications, ${ }^{32-34}$ along with manipulating hydrogen bonding and $\pi-\pi$ stacking to fine-tune the properties of Tyr. OMeY, with its low reduction potential while being relatively stable to $\mathrm{O}_{2}$, has been added as a unique member to the toolbox of Tyr analogs $\mathrm{s}^{35-37}$ for studying and engineering Tyrcontaining enzymes.

\section{Acknowledgements}

We thank the Shanghai Synchrotron Radiation Facility beamline scientists for their technical support during crystal diffraction data collection. We gratefully acknowledge the Major State Basic Research Program of China (2015CB856203, 2011CBA00800), National Science Foundation of China (21325211, 90913022, 31270859 21473237) and MOST innovation funds (14C26211100178) to J.W., and National Institutes of Health (GM06221) to Y.L.

\section{Notes and references}

1 R. Das and D. Baker, Annu. Rev. Biochem., 2008, 77, 363-382. 2 J. B. Siegel, A. Zanghellini, H. M. Lovick, G. Kiss, A. R. Lambert, J. L. St Clair, J. L. Gallaher, D. Hilvert, M. H. Gelb, B. L. Stoddard, K. N. Houk, F. E. Michael and D. Baker, Science, 2010, 329, 309-313.

3 W. F. DeGrado, C. M. Summa, V. Pavone, F. Nastri and A. Lombardi, Annu. Rev. Biochem., 1999, 68, 779-819.
4 G. Grigoryan, Y. H. Kim, R. Acharya, K. Axelrod, R. M. Jain, L. Willis, M. Drndic, J. M. Kikkawa and W. F. DeGrado, Science, 2011, 332, 1071-1076.

5 R. L. Koder, J. L. Anderson, L. A. Solomon, K. S. Reddy, C. C. Moser and P. L. Dutton, Nature, 2009, 458, 305-309.

6 T. K. Hyster, L. Knorr, T. R. Ward and T. Rovis, Science, 2012, 338, 500-503.

7 P. S. Coelho, E. M. Brustad, A. Kannan and F. H. Arnold, Science, 2013, 339, 307-310.

8 Y. Li, B. Wang, Y. Luo, D. Yang, P. Tong, J. Zhao, L. Luo, Y. Zhou, S. Chen, F. Cheng and J. Qu, Nat. Chem., 2013, 5, 320-326.

9 A. J. Reig, M. M. Pires, R. A. Snyder, Y. Wu, H. Jo, D. W. Kulp, S. E. Butch, J. R. Calhoun, T. Szyperski, E. I. Solomon and W. F. DeGrado, Nat. Chem., 2012, 4, 900-906.

10 M. S. Rogers, E. M. Tyler, N. Akyumani, C. R. Kurtis, R. K. Spooner, S. E. Deacon, S. Tamber, S. J. Firbank, K. Mahmoud, P. F. Knowles, S. E. Phillips, M. J. McPherson and D. M. Dooley, Biochemistry, 2007, 46, 4606-4618.

11 K. Kano, T. Mori, B. Uno, M. Goto and T. Ikeda, Biochim. Biophys. Acta, Gen. Subj., 1993, 1157, 324-331.

12 J. W. Whittaker, Chem. Rev., 2003, 103, 2347-2363.

13 P. A. Frey, A. D. Hegeman and G. H. Reed, Chem. Rev., 2006, 106, 3302-3316.

14 J. Stubbe and W. A. van der Donk, Chem. Rev., 1998, 98, 705762.

15 V. R. Kaila, M. I. Verkhovsky and M. Wikstrom, Chem. Rev., 2010, 110, 7062-7081.

16 B. Diner and R. D. Britt, in Photosystem II, ed. T. Wydrzynski, K. Satoh and J. Freeman, Springer, Netherlands, 2005, vol. 22, ch. 10, pp. 207-233.

17 M. Wikstrom, Biochim. Biophys. Acta, Bioenerg., 2012, 1817, 468-475.

18 D. A. Pratt, R. P. Pesavento and W. A. van der Donk, Org. Lett., 2005, 7, 2735-2738.

19 X. Liu, Y. Yu, C. Hu, W. Zhang, Y. Lu and J. Wang, Angew. Chem., Int. Ed., 2012, 51, 4312-4316.

20 K. D. Miner, A. Mukherjee, Y.-G. Gao, E. L. Null, I. D. Petrik, X. Zhao, N. Yeung, H. Robinson and Y. Lu, Angew. Chem., Int. Ed., 2012, 51, 5589-5592.

21 Y. Yu, X. Lv, J. Li, Q. Zhou, C. Cui, P. Hosseinzadeh, A. Mukherjee, M. J. Nilges, J. Wang and Y. Lu, J. Am. Chem. Soc., 2015, 137, 4594-4597.

22 L. Alfonta, Z. Zhang, S. Uryu, J. A. Loo and P. G. Schultz, J. Am. Chem. Soc., 2003, 125, 14662-14663.

23 M. R. Seyedsayamdost, J. Xie, C. T. Chan, P. G. Schultz and J. Stubbe, J. Am. Chem. Soc., 2007, 129, 15060-15071.

24 S. Ito and K. Wakamatsu, Photochem. Photobiol., 2008, 84, 582-592.

25 M. R. Seyedsayamdost, S. Y. Reece, D. G. Nocera and J. Stubbe, J. Am. Chem. Soc., 2006, 128, 1569-1579.

26 X. Liu, J. Li, C. Hu, Q. Zhou, W. Zhang, M. Hu, J. Zhou and J. Wang, Angew. Chem., Int. Ed., 2013, 52, 4805-4809.

27 S. G. Lee, S. P. Hong, Y. H. Choi, Y. J. Chung and M. H. Sung, Protein Expression Purif., 1997, 11, 263-270. 
28 Q. Zhou, M. Hu, W. Zhang, L. Jiang, S. Perrett, J. Zhou and J. Wang, Angew. Chem., Int. Ed., 2013, 52, 1203-1207.

29 A. S. Pawate, J. Morgan, A. Namslauer, D. Mills, P. Brzezinski, S. Ferguson-Miller and R. B. Gennis, Biochemistry, 2002, 41, 13417-13423.

30 Y. Yu, A. Mukherjee, M. J. Nilges, P. Hosseinzadeh, K. D. Miner and Y. Lu, J. Am. Chem. Soc., 2014, 136, 11741177.

31 J. J. Warren, J. R. Winkler and H. B. Gray, FEBS Lett., 2012, 586, 596-602.

32 Y. K. Lee, M. M. Whittaker and J. W. Whittaker, Biochemistry, 2008, 47, 6637-6649.
33 T. Tsukihara, H. Aoyama, E. Yamashita, T. Tomizaki, H. Yamaguchi, K. Shinzawa-Itoh, R. Nakashima, R. Yaono and S. Yoshikawa, Science, 1996, 272, 1136-1144.

34 S. Yoshikawa, K. Shinzawa-Itoh, R. Nakashima, R. Yaono, E. Yamashita, N. Inoue, M. Yao, M. J. Fei, C. P. Libeu, T. Mizushima, H. Yamaguchi, T. Tomizaki and T. Tsukihara, Science, 1998, 280, 1723-1729.

35 J. A. Cotruvo and J. Stubbe, Annu. Rev. Biochem., 2011, 80, 733-767.

36 C. C. Liu and P. G. Schultz, Annu. Rev. Biochem., 2010, 79, 413. 37 C. Hu, S. I. Chan, E. B. Sawyer, Y. Yu and J. Wang, Chem. Soc. Rev., 2014, 43, 6498-6510. 